\title{
Quem comemora o dia das mães: discurso, mídia e gênero
}

\section{Who celebrates mother's day: discourse, media, and gender}

\author{
Samuel Barbosa Silva ${ }^{1}$
}

DOI: $10.28998 / 2317-9945.2019 n 63 p 83-93$

\section{Resumo}

A midia - principalmente a televisiva - tem se utilizado da mulher para promover o consumo em seus anuncios a fim de atender às necessidades da lógica do mercado capitalista. Neste trabalbo, identificamos na sociedade hodierna discursos que lidam com a representatividade da mulher. Sendo assim, temos por objetivo desvelar os efeitos de sentido que são construídos sobre o lugar e as funçoes sociais ocupadas pela mulher (mãe) na atualidade. Utilizamos o aporte teórico da Análise de Discurso (doravante AD), ancorada no materialismo histórico ${ }^{2}$, composta pelo discurso como objeto de análise da materialidade discursiva.

Palavras-chave: Capital. Mulher. Discurso

\begin{abstract}
The media - especially television - has used women in their ads to promote consumption in order to meet the needs of the capitalist market logic. In this work, we identify in today's society many discourses which deal with the representation of women. Thus, we aim to unveil the meaning effects regarding the place and social functions occupied by the woman (mother) in the present day. We use the theoretical contribution of Discourse Analysis (hereinafter AD), which is anchored in historical materialism and understands discourse as the object of analysis of the discursive materiality.
\end{abstract}

Keywords: Capital. Woman. Discourse

Recebido em: 27/02/2019.

Aceito em: 11/05/2019.

\footnotetext{
${ }^{1}$ Doutorando e mestre em Linguística pelo Programa de Pós-graduação em Linguística e Literatura da Universidade Federal de Alagoas.

2 A base teórica da AD é respaldada pelo materialismo dialético, que considera o discurso como concreto, isto é, sua análise é feita a partir da realidade objetiva considerando o processo histórico-ideológico.
} 


\section{Introdução}

O discurso midiático é uma grande ferramenta de comunicação de massa presente no corpo social. Sendo assim, é capaz de produzir diversos efeitos de sentido a respeito de qualquer assunto recorrente na sociedade. A mídia - principalmente a televisiva - tem utilizado também a mulher para promover o consumo em seus anúncios, a fim de atender às necessidades dialógicas do mercado capitalista.

Neste trabalho, identificamos que a propaganda da Vitarella ${ }^{3}$ (2008) sustenta discursos que tratam sobre a representatividade da mulher na sociedade hodierna. Sendo assim, temos por objetivo desvelar os efeitos de sentido que são construídos sobre o lugar e as funções sociais ocupadas pela mulher (mãe) na atualidade.

Dessa forma, a Vitarella se apropria do discurso que é dirigido socialmente para a mulher que se torna mãe, causando efeitos de evidência semelhantes aos consumidores/telespectadores de forma ampla, ratificando assim a comercialização dos seus produtos. Ademais, contribui para a opressão do gênero feminino ao enfatizar determinadas formas de manifestação da linguagem, através do discurso, que viabilizam a subalternização da mulher para a promoção do capital.

Utilizamos o aporte teórico da Análise de Discurso (doravante AD) ancorada no materialismo histórico, composta pelo discurso como objeto de análise da materialidade discursiva.

\section{O discurso e suas categorias: breves considerações}

A base teórico-metodológica para análise e discussão deste trabalho está alicerçada na Análise de Discurso fundada por Michel Pêcheux (1969). Como a AD, em sua gênese, elucida a importância da teoria materialista do discurso ${ }^{4}$, debruçar-nos-emos sob esta perspectiva, pois "a concepção materialista da história parte da tese de que a produção, e com ela a troca dos produtos, é a base de toda ordem social [...]” (ENGELS, 1988, p. 54).

Esta perspectiva possui como objeto de estudo o discurso que é:

[...] a objetividade feita subjetividade, através de um pôr social feito de linguagem. [...] Lugar onde se produzem os sentidos. Tais sentidos podem ser reconhecidos pelas formulações - materialidades discursivas - em que sujeitos e sentidos se constituem (FLORÊNCIO et al., 2009, p. 48; p. 63).

Algumas categorias pertinentes à $\mathrm{AD}$ foram requisitadas pela materialidade discursiva em análise no momento do gesto de interpretação, realizado a partir da contradição representada nos discursos que são materializados nas relações sociais capitalistas, já que "o

\footnotetext{
3 A marca Vitarella nasceu em 1993, em Jaboatão dos Guararapes, Pernambuco. Inicialmente com apenas 30 colaboradores e focada na produção de massas alimentícias, a unidade expandiu seu portfólio e hoje possui mais de 100 produtos cadastrados, atuando também no segmento de biscoitos, como crackers, rosquinhas, recheados, wafers, amanteigados, tortinhas, entre outros - e marcas como Treloso, Chocoresco e Saltvip. Em 2008, a Vitarella foi adquirida pela também nordestina M Dias Branco, maior fabricante de massas e biscoitos da América Latina, com 12 fábricas instaladas no Nordeste, Sudeste e Sul do País.

4 Ver Semântica e Discurso, Michel Pêcheux (1997).
} 
modo de produção da vida material condiciona o processo de vida social, política e intelectual” (MARX, 1983, p. 47).

Costurando essas considerações iniciais, destacaremos as categorias das formações ideológicas (FI) e formações discursivas (FD) como imprescindíveis no processo discursivo, uma vez que as FI possuem uma ou várias FD, sendo assim indissociáveis. Pêcheux (1993) sublinha:

[...] uma formação discursiva existe historicamente no interior de determinadas relações de classes; pode fornecer elementos que se integram em novas formações discursivas, constituindo-se no interior de novas relações ideológicas, que colocam em jogo novas formações ideológicas (PÊCHEUX, 1993, p. 167-168).

Tais formações ideológicas são materializadas nas relações sociais, mediadas pelo discurso, que na formação social contemporânea agregam valores contraditórios. Por isso, também podemos dizer que na atualidade há duas modalidades de FI: a do capital (individualista - que visa à continuidade das relações de produção) e a do trabalho (coletividade - que visa à transformação das relações de produção). "São essas [...] que orientam a prática da sociedade capitalista, sob a dominância da primeira, por ser a ideologia da classe dominante" (AMARAL, 2007, p. 25).

As categorias do intradiscurso, interdiscurso e memória discursiva carregam em si entrelaçamentos que viabilizam a conexão entre o sujeito e o discurso, possibilitando assim ressignificar os dizeres a partir do que já foi dito em um dado momento da história. Isto é, "os discursos formulados (interdiscurso) que permitem o dizer (intradiscurso)" (FLORÊNCIO et al., 2009, p. 77).

Como em todo processo discursivo, as formações imaginárias estão presentes ressaltando lugares e/ou representações específicas que são conferidos ao se produzir discurso em qualquer circunstância. Estas, por sua vez, utilizam-se de mecanismos (relações de força, relações de sentido, antecipação) para o funcionamento discursivo. Pêcheux (1993) reforça:

[...] se assim ocorre, existem os mecanismos de qualquer formação social regras de projeção, que estabelecem as relações entre as situações (objetivamente definíveis) e as posições (representações dessas situações). Acrescentemos que é bastante provável que esta correspondência não seja biunívoca, de modo que diferenças de situação podem corresponder a uma mesma posição, e uma situação pode ser representada como várias posições (PÊCHEUX, 1993, p. 82-83).

Asseveramos também que há silêncio produzido pelos sujeitos, produzindo novos sentidos, abarcando assim novas formas de significar na realidade objetiva. Por sua vez, não se confunde com o ato de calar, mas é uma nova forma de expressividade no meio social, tonificando assim múltiplos sentidos, como aponta Orlandi (2001, p. 72), o sujeito passa "das palavras ao silêncio e do silêncio às palavras". 


\section{Análise e discussões}

A materialidade discursiva selecionada para análise é uma propaganda da empresa Vitarella, veiculada na mídia televisiva no período do dia das mães no ano de $2008^{5}$. Já que o discurso está filiado às condições sócio-históricas, é coerente tratar de uma categoria fundamental neste processo de análise, que são as condições de produção do discurso, segundo Pêcheux (1993, p. 77) "[...] um discurso é sempre pronunciado a partir de condições de produção dadas". Orlandi (2009) vai dividir essas condições de produção em "amplas" e "restritas".

As condições de produção amplas para esta materialidade outorgam-se ao papel historicamente atribuído à mulher que se torna mãe, como aquela única responsável pelos cuidados (saúde, educação, alimentação, etc.) nas várias etapas da vida de seus filhos dentro/fora do lar. Para efetivação ideológica deste papel, o patriarcado ${ }^{7}$, enquanto sistema, funciona discursivamente para manutenção desse comportamento, consolidando as atividades da mulher em seu cotidiano a partir de sua função biológica, pois é capaz de gestar/aleitar. Então, uma de suas "tarefas domésticas" é preparar seus filhos para o âmbito público e/ou privado na sociedade ${ }^{8}$.

As condições restritas de produção da materialidade evidenciam a trajetória de vida de uma mulher (mãe) com a sua filha, acompanhando-a em algumas das fases de existência do ser humano (desde o nascimento até a adolescência). Na sequência de imagens, a mulher (mãe) aparece cuidando/responsabilizando-se pelo bom desempenho de sua filha: dar banho, levar até a sua primeira escola, brincar, comer, brigar, aprender a se maquiar juntas e participar indiretamente do primeiro momento de saída da filha com suas amigas.

A propaganda finaliza com um almoço em família, em que a filha acompanha a preparação de uma macarronada feita pela mãe e ambas a levam para a mesa, que está arrumada e é composta por mulheres (mãe, filha e avó e estão em pé) e homens (pai e avô), que já estão sentados na mesa (ambos nas extremidades) aguardando o prato a ser servido e batem palmas com a chegada do alimento. Mãe e filha comem bolachas sentadas na praça. No momento da sequência de imagens do almoço, o locutor afirma: "A sua família é o mais importante pra você. E pra gente também. (SD1) Vitarella, produtos feitos com carinho como a sua família gosta" (SD 2) (Durante todo o percurso da propaganda há trechos da música Pensando em Vocế).

\footnotetext{
${ }^{5}$ Link da materialidade analisada: <https://www.youtube.com/watch?v=KWBkWSqxcrU>. Acesso em: 21 maio 2019.

${ }^{6}$ Segundo Orlandi (2009), as condições de produção amplas se referem ao contexto sócio-histórico-ideológico de produção de determinado discurso, enquanto as condições restritas se referem às condições imediatas do discurso produzido pelos sujeitos.

${ }^{7}$ Sobre esse conceito, ver Saffioti (2015), Gênero, patriarcado e violência.

${ }^{8}$ É com a chegada da sociedade capitalista que se consolida e se institucionaliza naturalmente os lugares que devem ser ocupados por homens e mulheres, estas no privado e aqueles no público, garantindo assim a continuidade e dispersão do novo modelo de formação social: a capitalista (Produção e Reprodução dos meios materiais). Destaca-se que apenas depois de meados do século XX as mulheres de alguns países desenvolvidos (depois de certo tempo, consequentemente, alcançaram alguns países subdesenvolvidos), com a primeira e segunda onda do movimento feminista, asseguraram determinados direitos, sendo um deles o direito ao trabalho fora do lar, independentemente da aprovação do pai, irmão, marido. Ver Mendéz (2005), Do lar para as ruas: capitalismo, trabalho e feminismo.

${ }^{9}$ Música e letra de autoria do cantor e compositor Paulinho Moska: "Pensando em você".
} 
O discurso do locutor serão as sequências discursivas $\left(\mathrm{SD}^{10}\right)$ analisadas emparelhadas com as condições de produção que asseveram a circulação desses dizeres. Uma vez que todo discurso está condicionado ao processo histórico-social, como afirma Pêcheux (1993):

[...] o estudo da ligação entre as circunstâncias de um discurso - que chamaremos daqui em diante suas condições de produção - e o seu processo de produção. Esta perspectiva está representada na teoria linguística atual pelo papel dado ao contexto ou à situação, como pano de fundo específico dos discursos, que torna possível sua formulação e sua compreensão (PÊCHEUX, 1993, p. 75).

Na materialidade analisada, alguns questionamentos iniciais são apresentados: quais os efeitos de sentido que são gerados e produzidos sobre a mulher (mãe) na propaganda da Vitarella? Qual o discurso da Vitarella sobre o lugar da mulher na sociedade? Como essa propaganda pode refletir nas práticas discursivas dos sujeitos na continuidade e preservação da sociedade capitalista?

Esses sujeitos presentes na materialidade respondem a condições materiais específicas de uma formação social, isto é, a propaganda analisada está vinculada à sociedade capitalista, assumindo assim determinada posição social e discursiva ${ }^{11}$. Essa posição reflete e refrata uma sociedade que tem como cerne o antagonismo social, ou seja, há a existência de classes sociais (burguesia e proletariado) com interesses divergentes que lutam pela continuidade ou transformação da sociedade e é no capitalismo que a consolidação das classes sociais acontece, trazendo a contradição, a propriedade privada, a exploração do trabalhador através da mais-valia obtida na produção/reprodução das formas materiais de subsistência.

Essa posição-sujeito corresponde primariamente a formações ideológicas apropriadas pelo sujeito e entram em consonância ou conflito com a ideologia dominante (burguesa/capital). Sendo assim, os sentidos presentes no discurso da propaganda da Vitarella estão condicionados às formações ideológicas, como já aponta Pêcheux (1997, p. 146): "Diremos que o caráter material do sentido [...] consiste na sua dependência constitutiva daquilo que chamamos 'o todo complexo das formações ideológicas".

O discurso publicitário apresenta a todo o momento as funções sociais que são atribuídas à mulher-mãe, produzindo efeitos de evidência nos sujeitos consumidores, apontando qual deve ser a função desempenhada primordialmente por toda mulher: ser mãe. As estratégias discursivas iniciam com a escolha da música "Pensando em você" que vai compor todo o cenário propagandístico. Uma música que traz em sua composição elementos linguísticos que são atribuídos ao afeto, à doçura, ao cuidado, ao zelo, etc. por alguém/alguma coisa, construindo assim no imaginário dos sujeitos uma "romantização" e/ou "vocação" do que deseja ser evidenciado pelo filme publicitário.

A música, nesse momento, é utilizada produzindo efeitos de sentido sobre a mulhermãe na sociedade, reforçando assim para qual função a mesma está "predestinada". Essa "romantização" satisfaz as relações de controle e poder sobre a mulher, utilizando-a como um fetiche mercadológico nas relações de trabalho. Para que o capital possa ganhar fôlego, é necessário atender a demanda das relações de produção que tem em seu funcionamento a

\footnotetext{
$10 \mathrm{SD}$, na análise de discurso, se refere à sequência discursiva.

11 Pêcheux (1997, p. 171-172) afirma que "a tomada de posição do sujeito apresenta-se como um efeito discursivo resultante da interpelação ideológica".
} 
produção/reprodução material como elementos fundadores. A mulher leva consigo uma das mais importantes "tarefas" biológicas que garante a manutenção desta sociedade: o ato da reprodução. Para isso, a ideologia é um mecanismo essencial, porque:

[...] na sociedade capitalista a ideologia encontra formas para cumprir a sua função específica: dissimular evidências de parcerias entre as classes para manutenção da ordem vigente, a de dominância do capital. Uma dessas formas é identificada como a formação ideológica que 'promulga' e faz vigorar ideias, os valores do capitalismo, a que chamamos de formação ideológica do capitalismo (AMARAL, 2007, p. 25).

A ideologia dominante (capital) no discurso da Vitarella traz em sua constituição a representação da mulher (mãe), independentemente da classe social, na sociedade contemporânea e "convida" os consumidores a fortalecerem os padrões de comportamentos de uma sociedade patriarcalista, de forma velada, mantendo assim a hierarquia de poderes partindo da escolha do gênero feminino, deslocando-o para o âmbito privado. A mulher, por ser capaz de gerar outro ser em seu ventre (ato da maternidade), que possivelmente servirá para a perpetuação do sistema vigente, é relegada a desenvolver atos de maternagem porque essa criança necessita de cuidados de alguém que garanta uma vida saudável e estável para adentrar no mercado de trabalho no tempo oportuno.

A lógica capitalista promove a mulher a uma situação de subalternidade/opressão social através de discursos que viabilizam o engendramento do capitalismo, consequentemente da submissão das mulheres aos homens. $O$ discurso da paternidade/paternagem é silenciado devido ao processo sócio-histórico das relações de poder que foram se institucionalizando como aquele que é o "provedor do lar" e, portanto, não deve se preocupar com as atividades domésticas/paternagem.

No entanto, as ideologias patriarcais e religiosas atuais reforçam que esse "serviço" ou "santa missão" é da figura feminina, pois se ela é capaz de gerar um bebê, então ela é "vocacionada"/"predestinada" a ter a responsabilidade na formação deste ser humano, garantindo assim os cuidados necessários para o bem-estar desta criança/adolescente.

A Vitarella utiliza-se de marcas discursivas para enfatizar comportamentos no ser social que são próprios para o movimento desta sociedade, visto que são nos discursos constituídos, formulados e postos em circulação que serão base fundamental, orientando as práticas sociais dos sujeitos.

$\mathrm{Na}$ sequência "A sua familia é o mais importante pra você. E pra gente também”, podemos acionar as categorias do intradiscurso, interdiscurso, silêncio e formaçôes discursivas (FD) para análise, pois tal discurso provoca efeitos de sentido nos interlocutores a partir do que está sendo dito, já que "o discurso se constrói na sua identidade com o outro" (AMARAL, 2007, p. 30).

No intradiscurso temos a utilização de elementos morfossintáticos que cooperarão para o funcionamento discursivo, isto é, no fio do discurso é possível detectar a presença do interdiscurso. Ao utilizar o pronome "sua" subjaz a ideia de posse de algo/alguém que será determinado pelo filme publicitário se referindo à "família". Essa será a responsabilidade primordial, confirmada em seguida com o verbo "é" indicando a ação/posicionamento que deve ser assumido por "você".

Na sociedade capitalista, a responsabilidade dos cuidados (educação, saúde, etc.) com a família é colocada sobre a mulher para que ela possa gerenciar as atividades domésticas 
(não-remuneradas) ${ }^{12}$ e certificar o bom desempenho nas primeiras fases da vida dos seus filhos, enquanto ao homem coube o espaço público vendendo a força de trabalho (remunerada). Tais responsabilidades equiparam-se apenas na extração da mais-valia, pois é retirada de ambos de formas diferenciadas ${ }^{13}$.

No decorrer da propaganda da Vitarella, essa responsabilidade continua sendo enfatizada apenas para a mulher, agregando compromissos que a mesma deve obter com a família (esta representa o lugar social do âmbito privado). Além das imagens presentes na propaganda, o pronome "você" destaca efeitos de sentido que são direcionados para alguém específico, neste caso, um gênero específico: feminino. O substantivo "importante" opera como elemento mediador entre a ação (também fortalecida pelo verbo "é") que deve ser executada e por alguém que deve exercê-la, uma vez que a família está sob a incumbência de "você", isto é, a supervisão para a harmonia e o bem-estar do lar e dos filhos é predestinada socialmente ao sexo feminino.

O interdiscurso opera na formulação desse dizer atribuindo sentidos que ratificam com a ideologia capitalista sobre qual deve ser o lugar e as funções exercidas pela mulher na sociedade, arraigada com princípios da exploração de trabalho (não há o reconhecimento das atividades domésticas como trabalho) e dominação masculina.

No processo de formulação o sujeito não tem domínio sobre a variedade de sentidos possíveis do seu dizer e por isso procura, às vezes, dar conta do equívoco, da falha permitida pela ação da língua, através de uma relação de paráfrase (AMARAL, 2007, p. 31).

O processo parafrástico no discurso publicitário, que causa o efeito de evidência de enaltecimento da mulher (mãe), está articulado com outros dizeres, outras vozes, já ditas em vários momentos da história acerca do lugar e funções desempenhadas pela mulher, tornando-se assim contraditório com uma possível "homenagem" às mulheres mães, porque ainda tonifica o setor privado como exclusividade/prioridade do sexo feminino.

Finalizando a análise da SD1, temos a presença do "E pra gente também."; quem representa esse "a gente"? E porque é importante para esse "a gente"? Esse pronome informal, além de proporcionar sentido de proximidade com o consumidor da região onde serão vendidos os produtos em sua maioria (Nordeste), também localiza o sujeito (Indústria Vitarella) que aparenta ter esse mesmo "cuidado", "zelo", que apenas uma mulher (mãe) poderia ter, já que a ideologia sobre as funções sociais atribuídas à mãe na sociedade funciona nesta mesma direção.

Mas nesta formação discursiva não é apenas “importante” para o consumidor saber que está adquirindo um produto de qualidade, há um silêncio sobre a importância para a empresa de manter a mulher cuidando da casa e dos filhos com a finalidade de garantir a ordem da reprodução social e pessoas sadias que perpetuem a lógica do capitalismo. A Vitarella, por ocupar um lugar discursivo que atende a permanência da sociedade capitalista, traz nesta formação discursiva o que pode e deve ser dito pela posição-sujeito a qual a indústria inscreve seus dizeres, dentro de uma conjuntura de relação de classes, contradições sociais.

Na SD2 temos "Vitarella, produtos feitos com carinho como a sua família gosta". As categorias da memória discursiva, formações imaginárias (FI) e Formação Discursiva do Mercado

12 Ver Magalhães \& Silva (2015): Capitalismo e patriarcalismo: trabalho doméstico não remunerado.

13 Ver Saffioti (2013): A mulher na sociedade de classes: mito e realidade. 
(FDM) são convocadas para esta outra parte da análise. Ao tomarmos o discurso "Vitarella, produtos feitos com carinho [...]”, está explícita a presença da FDM. Amaral (2005) define esta categoria como:

[...] a Formação Discursiva do Mercado se define como um lugar de encontro entre elementos de saber já sedimentados; ou seja, elementos pré-construídos, produzidos em outros discursos, que são convocados no interior dessa formação discursiva, quer seja para serem confirmados, quer seja para serem negados, mas sempre para organizar os discursos que a representam; [...] Os elementos de saber da Formação Discursiva do Mercado estão ancorados em fundamentos da formação ideológica capitalista que considera que para a felicidade e a liberdade do homem só existe um caminho: seguir as determinações do mercado (AMARAL, 2005, p. 137).

A introdução da SD2 sinaliza a "Vitarella" como a marca capaz de promover aquele mesmo sentimento de carinho, cuidado e confiança que apenas a mulher (mãe) pode oferecer, trazendo assim em seu produto a personificação do sujeito. Tais produtos oferecidos seguem o padrão de qualidade e atenção que a função social da mulher-mãe (maternagem) exerce na sociedade capitalista. Neste momento, a memória discursiva é convocada nos consumidores, apelando assim para o percurso de sua vida em que a maioria deles se identifica com o discurso publicitário.

Também sob a mesma ótica, os mecanismos de funcionamento do discurso abrem espaço para as formações imaginárias que são construídas sobre a mulher e o produto a ser vendido para ecoar efeitos de sentido específicos no destinatário (consumidor), ou seja, o sujeito do discurso (representado pela empresa Vitarella) propaga uma publicidade que acentue com o esperado e promovido por ela e alcance satisfatoriamente o seu locatário. "Todo imaginário é cultural, produzido historicamente. [...] É válido acrescentar que as formações imaginárias se produzem e reproduzem historicamente, através das formações discursivas" (CARVALHO, 2012, p. 126).

Sendo assim, é construída no imaginário dos consumidores a imagem da mulher (mãe) que deve ter a obrigatoriedade de cumprir com todas as funções que foram atribuídas a ela socialmente, assim favorecendo o capital a manter sua estrutura na sociedade. Além disso, a figura masculina fica desobrigada de cumprir com seus deveres de paternagem, sobrecarregando a mulher que assume uma dupla/tripla jornada de trabalho na atualidade.

Ademais, esse carinho que a Vitarella evoca em seu discurso fantasia uma situação de que apenas a mulher, pelo fato de gestar, está apta para oferecê-lo. E mesmo o homem contribuindo geneticamente para que aquele bebê viesse a nascer, "não consegue" ofertar tão quanto a mulher (mãe), lembrando também o princípio de caridade ${ }^{14}$.

Acrescentamos as nossas informações com a análise final da SD2 quando diz: "[...] como a sua família gosta". O como funciona como uma figura de linguagem comparativa (carinho/cuidado de mãe = carinho/cuidado da Vitarella), além disso, abre precedentes de que o ato de subalternidade/submissão em nome do bem-estar da família deve ser prioridade do sexo feminino, já que na SD1 verificamos um possível sentido na escolha do pronome "você", de acordo com as condições de produção elucidadas pela propaganda. Então, se a

${ }^{14}$ Ver Teixeira (2015): Das damas de caridade às trabalbadoras: uma análise sobre o serviço social na historiografia da educação brasileira. 
família faz parte da responsabilidade da Vitarella (que se personifica através da mulher-mãe), também gera efeitos de sentido que a mulher deve se comportar/se adequar/cumprir funções sociais "como a sua família gosta".

A propaganda analisada reforça o movimento dos sentidos, através dos discursos, que são constituídos, formulados e postos em circulação a partir da FDM presente nestas sequências discursivas. Cria uma ilusão no sujeito de "felicidade" e "liberdade" no momento da aquisição do produto, velando a "prisão" mercadológica a qual está submetido. Além disso, colabora para a estigmatização do gênero feminino enfatizando o que deve ou não fazer/dizer/assumir para o "bom" funcionamento da sociedade hodierna, ratificando o que Pêcheux (1997) vai chamar de "bom sujeito".

Neste jogo discursivo entre a mercadoria ${ }^{15}$ ofertada pela Vitarella e as funções sociais atribuídas à mulher (mãe), há sentidos outros que são provocados e encaminham a fortes interesses sociais da ideologia dominante, conduzindo a permanência do capital e, por conseguinte, a exploração da mulher em uma sociedade dividida por classes sociais com finalidades diferentes. Apenas a transformação da realidade objetiva pelo ser social, dentro das possibilidades ofertadas, é capaz de romper com esse modo de funcionamento de uma dada formação social, já que "a história de toda a sociedade até hoje é a história da luta de classes” (MARX; ENGELS, 1998, p. 4).

\section{Considerações finais}

Com as contribuições proporcionadas pela base teórico-metodológica da Análise de Discurso (AD) foi possível mobilizar algumas categorias a partir de pressupostos teóricos que auxiliaram no processo de descorporificação da materialidade discursiva.

A propaganda da Vitarella traz em seu cerne particularidades que estão imbricadas com a ideologia dominante no que se refere à questão do gênero feminino e à circulação das mercadorias vigentes. Existe um "empoderamento" por parte da indústria alimentícia acerca dos papeis sociais desempenhados pela mulher na condição de mãe com objetivos de obter lucro sobre a venda destas mercadorias a partir da comoção sentimental dos seus clientes/consumidores em um momento de grande expressividade no cenário brasileiro: $\mathrm{O}$ dia das mães.

No entanto, a propaganda proporciona outros efeitos de sentido a partir da linguagem adotada, que constitui o escopo da materialidade. Dessa forma, as mulheres passam a ocupar sua rotina cotidiana apenas na área privada e funções sociais peculiares na sociedade moderna, (re)produzindo assim dizeres que adequem a mulher à necessidade do capital.

A figura masculina é convocada apenas no momento de cercar a mesa, ocupando lugares da extremidade, mais precisamente, mobilizando uma memória sócio-histórica do patriarcalismo (homens devem sempre ser servidos pelas mulheres) e representando assim

\footnotetext{
15 O conceito de mercadoria para Marx (2014) refere-se ao que se produz para o mercado com valor de venda e não apenas do uso imediato do produtor. Ver Marx (1985), O Capital.
} 
relações de poder entre os gêneros (masculino/feminino) institucionalizados ao longo da história.

A maternagem passa a imperar todo o cenário, exaltando esta função como soberana de toda a mulher e, havendo resistência por parte de alguma mulher-mãe (caso queira adentrar o mercado de trabalho, por exemplo), não poderá acompanhar e proporcionar todo aquele amor, cuidado, carinho, etc. na trajetória do(s) seu(s) filho(s), ficando também a mercê da sociedade que vai "cobrar" a responsabilidade do(s) filho(s) exclusivamente à mulher. Enquanto isso, as ocupações laborais de prestígio - do âmbito público - são transferidas para o homem e a cobrança social pelos filhos quase não existe, praticamente silenciada.

Essa propaganda reflete nas práticas discursivas dos sujeitos (independentemente do gênero) na continuidade e preservação da sociedade capitalista, porque seu âmago é constituído pela exploração do trabalhador na venda desses produtos e obtenção da maisvalia. Além disso, confere à mulher posições sociais apenas de subalternização para o crescimento do capitalismo. Sendo assim, é importante frisar que a mulher, na atual sociedade, sofre uma opressão não apenas pelo que o sistema já impõe (exploração de trabalho), mas pelo fato de ser mulher. Há acréscimos não vivenciados pelos homens, ou seja, torna-se propriedade privada e de exploração de todas as formas possíveis (controle da sua sexualidade/subjetividade no processo histórico).

Consideramos a necessidade de se sobressair a esse modelo de formação social que privilegia certas classes sociais, pois é a partir dele que as desigualdades sociais são postas na realidade, privilegiando uma determinada classe social (burguesia) com a exploração do trabalho e consequentemente a extração da mais-valia da grande massa que compõe a sociedade planetária, isto é, a classe trabalhadora.

\section{Referências}

AMARAL, M. V. B. Discurso e relações de trabalho. Maceió: Edufal, 2005.

AMARAL, M. V. B. O avesso do discurso: análise de práticas discursivas no campo do trabalho. Maceió: Edufal, 2007.

CARVALHO, Maria Leônia Garcia Costa. A construção de uma discursividade feminista em Sergipe: a Revista Renovação na década de 1930. São Cristóvão: Editora UFS, 2012.

ENGELS, F. Do socialismo utópico ao socialismo científico. São Paulo: Global, 1988.

FLORÊNCIO, Ana Maria Gama et al. Análise do discurso: fundamentos \& práticas. Maceió: Edufal, 2009.

MARX, K.; ENGELS, F. A ideologia alemã: Feuerbach. São Paulo: Grijalbo, 1986.

MARX, K.; ENGELS, F. Manifesto do Partido Comunista. São Paulo: Cortez, 1998.

MARX, K. Contribuição à crítica da economia política. São Paulo: Martins Fontes, 1983. 
MARX, K. O Capital: crítica da economia política. Livro I, Tomo I. São Paulo: Nova Cultural, 1985.

MAGALHÃES, Belmira; SILVA, Geice. Capitalismo e patriarcalismo: trabalho doméstico não remunerado. In: VEDDA, M.; COSTA, N. A. (org.). Anuário Lukács 2015. São Paulo: Instituto Lukács, 2015, p. 213-246.

MÉNDEZ, N. P. Do lar para as ruas: capitalismo, trabalho e feminismo. Mulher e trabalho, Porto Alegre, v. 5, p. 51-63, 2005.

ORLANDI, Eni. Discurso e Texto: formulação e circulação dos sentidos. Campinas: Pontes, 2001.

ORLANDI, Eni. Análise de Discurso: princípios \& procedimentos. 8. ed. Campinas: Pontes, 2009.

PÊCHEUX, M. Análise de Discurso: as três épocas. In: GADET, Françoise; HAK, Tony. (org.). Por uma análise automática do discurso: uma introdução à obra de Michel Pêcheux. Tradução: Eni Puccinelli Orlandi. Campinas: Editora da Unicamp, 1993.

PÊCHEUX, M. Semântica e discurso: uma crítica à afirmação do óbvio. 3. ed. Campinas: Editora da Unicamp, 1997.

SAFFIOTI, H. A mulher na sociedade de classes. 3. ed. São Paulo: Fundação Perseu Abramo, 2013.

SAFFIOTI, H. Gênero, patriarcado, violência. 2. ed. São Paulo: Fundação Perseu Abramo, 2015.

TEIXEIRA, Michael Hermann Garcia. Das damas de caridade às trabalhadoras: uma análise sobre o serviço social na historiografia da educação brasileira. Práxis Pedagógica: Revista do Curso de Pedagogia, Aracaju, v. 2, n. 2, jan./jun. 2015. 